\title{
When is a Promise a Strategic Liability?
}

\author{
Synopsis
}

Employers offer pension plans for two main reasons: paternalism and skills market competitiveness. Recent changes in legislation and business practice have prompted the scrutiny of the underpinnings for such a management tradition. The paper identifies several relevant factors that derive from: field work undertaken by the authors; the Pensions Act 1995; and recent changes to corporations tax. It is argued that what has emerged is a sharply focused trade-off, relating to the asset and liability characteristics of employer-based pension schemes. This questions the sustainability of all types of pension plans, and thereby has a place in strategies affecting financial planning and business development.

Nicholas Terry and Phil White

Senior Lecturers

Department of Business Studies

University of Edinburgh

50 George Square

Edinburgh EH8 9JY 


\section{Introduction}

Most larger organisations in the UK offer some form of pension plan for employees. The choice of which arrangement to use, and how levels of funding can be maintained so as to provide for a meaningful benefit have been subject to significant recent debate, as has the appropriate legal framework under which such schemes should operate. The main issue for employers is to strike a balance between the cost, given that employers at least match employees' contributions, or contribute more, or provide the benefit with no employee contribution, and the effectiveness of pensions as a recruitment, motivation and retention device. Employers face with pensions a set of factors that require both managing cost and employees' expectations, and, given the nature of the arrangement, to do so over time periods likely to exceed anything found in strategy documents.

The two types of pension plans used widely in the UK are defined benefit (DB) or final salary, and defined contribution/cost (DC) or money purchase. The former calculates pension in relation to salary at the point of retiral, and is based upon the number of years of pensionable service (e.g., a maximum two-thirds of final salary pension assuming forty years of service - known as a "40/60ths" arrangement). Money purchase provides that level of pension available from buying an annuity at the time of retirement. The pension received is dependent both on the annuity rates ruling at the time (usually based on actuarial assumptions), and the value of the investment "pot" into which contributions have been paid (which will be a function of the total returns earned from the securities markets by the particular fund manager). Clearly, there is a risk, cost and flexibility trade-off present both for employees and employers as between the two types of plan.

Under DC schemes, the main risk for employees is the investment risk both of poor returns over the individual's working life, thereby reducing the size of the pot, and the likelihood that such market conditions would prompt unattractive annuity rates because actuarial assumptions are based on expected future income from the same set of markets.

Under DB schemes, the employer bears the investment risk should the returns fail to cover the guaranteed benefit. In which case, employers would come under pressure to make good any shortfall (rather than reduce benefits). Additional regulatory requirements associated with the Pensions Act, and the change in taxing company dividends, render pensions much more than before a strategic issue. In particular, there is potential for: 
- Exposure to significantly higher funding costs resulting in lower profits

- Loss of employee confidence in an age of empowered, mobile and knowledgeable workers

- Damage to company image and knock-on effects in skills market

- Trustees going to jail

- New kinds of risk, including regulatory compliance costs

\section{"Traditional" Employer Attitudes}

A managerial belief in being regarded as a "good" employer remains strong because it is widely recognised that individuals tend to be myopic in planning for providing adequate income for old age. "Adequate" here means preserving an existing, or being able to meet an expectation of a particular, life-style. Therefore, employers consider a pension plan not only as a means of providing competitive employment terms but also as a long-term financial arrangement that can most effectively be organised and administered, on behalf of employees, by employers at the work place (1).

As a recruitment, retention and motivation device, there is little evidence to suggest that employers undertake systematic, or regular, evaluations of the effect of pension schemes on labour market behaviour.

"No, we have not assessed its effectiveness. The company knows that the scheme is appreciated, it has got itself embedded in the culture. But the labour market has changed in the last five to ten years, and I do not know about now."

(Services) *

\footnotetext{
* The quotes are taken from interviews, conducted in early 1997, with managers responsible for company pension schemes. They were identified following a postal questionnaire of the leading 500 firms in Scotland. A fuller account of some of the postal survey results are reported on elsewhere (2).
} 
Remaining competitive is likely to have more to do with salary and other "immediate" benefits:

"If you didn't have it (a pension plan), you would notice it: it would cause difficulty in recruiting. I am not sure what kudos you get from that: the level of salary and a car are more important. Pensions are always in the future."

(Manufacturing)

However, industry "norms", and near-competitor comparisons are established by pension scheme advisers.

"We are constantly in touch with our pension advisers. If there is an industry 'norm', they would advise us. If there was a benefit ... then we would prove it." (Manufacturing)

Yet not much appears by employers to be made of the "true" value of this benefit, even when such comparisons flatter a particular scheme, especially where the employer's contribution is relatively high, and where other related benefits (e.g. death-in-service payments) are relatively attractive. However, during their field work, the authors discovered that a large utility company had sent letters to each of its senior managers indicating what the Company felt was the full worth of the components making up the renumeration package, drawing particular attention to the costs and benefits of the pension plan.

There exists some evidence indicating differences of emphasis regarding these managerial beliefs as between size of organisation and different industry sectors. For example: larger firms, and those in the financial services sector, appear more concerned with labour market conditions; smaller firms, and those in retailing, seem more concerned to secure, for themselves as an employer, a paternalistic image (1). One explanation for these differences is that the former types of organisations face some skills shortages, whilst the latter are keen to promote paternalism because history suggests they operate at a size and in sectors that are, in employment terms, less secure and less generous. 
Given the long-standing and long-lived nature of the commitment involved, employers can be seen to have been sleepy in terms of recognising the worth, costs, and strategic implications of adhering to such traditional beliefs.

\section{The Pensions "Promise"}

Human resources (HR) managers would probably examine the implications for employers pursuing management beliefs associated with pension plans by emphasising the extent to which pensions are part of the mechanism used by employers to "control" or influence employees (3). In this context, pension plans are an implied promise to employees which forms part of the employer's contribution to a contract with employees.

Another approach is to classify and calibrate both the existence and type of pension scheme offered according to the potential for contributing positively (an "asset"), or negatively ( a "liability"), to managing an organisation. Moreover, assets that are capable of several uses are often described as being "fungible". This approach may be seen to be particularly apposite when management choice is likely to be influenced by the extent to which there exists a range of chances of certain outcomes (that is, financial and other "risks" that are attached to continuing with a specific managerial belief). In this case, the liability set of characteristics attached to pension schemes can be seen as being "contingent". The promise here is different from (but equally important as) the HR view, and relates to the potential both for positive and negative affects upon company performance and its room to manoeuvre suggesting that pensions have financial and strategic dimensions.

\section{Pension schemes can be seen as an "asset" when:}

(i) used to fund early retirals so as to achieve costs reduction, or where a mis-match emerges between the skills profile of the existing work-force and that identified as being necessary for the business moving forward;

(ii) negotiating with employees "inherited" from business that have been acquired by purchase or by asset swaps, assuming that the "new" scheme is relatively attractive; and 
(iii) moving from defined benefit (or final salary) to defined contribution (or money purchase) schemes, or creating two parallel schemes where membership of each is age-related.

Pension schemes can be seen as a "liability" when:

(i) regulatory compliance costs (both "normal" and abnormal charges caused by adverse judgements, and levy-type costs) arise, and when unforeseen difficult capital market conditions affect adversely the value of scheme assets;

(ii) managing expectations regarding terms and conditions of employment in "new" business areas, reflecting diversification plans or re-organisations that create single business units (SBU), with the intention of providing greater operational autonomy for managers, including giving them the right to vary terms and conditions of employment; and

(iii) deciding the most effective way of delivering compensation packages, especially executive type schemes and "golden parachutes".

When viewed within an asset-liability structure, attitudes towards pension schemes are likely to be dependent upon whether a surplus exists. If there is a surplus, it can provide a ready source of apparently "cheap" or "free" funding to ease pressure elsewhere within the organisation. In such a case, a scheme would be seen as an asset by several areas of the organisation, not only the finance and HRM functions but by others keen to ensure that a particular project goes ahead, especially those development plans involving "new" areas of activity or business practice. Employees too are attracted to surpluses as providing means of enhancing pension benefits. Conversely, if there is no surplus, or worse still a shortfall, then it represents another claim upon resources resulting in the inevitable management query about its retention, whilst employers will avoid reductions in benefits.

The potential for a variation in the financial commitment involved in supporting schemes, of the sort that have traditionally been used in the UK, is the justification for adopting money purchase schemes. Although this trend should not be over-emphasised as defined benefit remains the dominant form of provision (4). Nonetheless, the changes that have occurred, 
and the likelihood of continued critical scrutiny of final salary schemes, serves to illustrate that employers are unwilling to make open-ended commitments to pensions provision.

Any such review of pension plans have a dynamic element: "what if:" questions are beginning to be asked more frequently, and are in addition to the "how much this time?" type of question. Such questions related to the extent to which higher levels of regulatory risk are affecting the market risks associated with particular investment strategies. The Pensions Act has had the effect of requiring schemes to crystallise some of the historically acceptable (but often disguised) risks, and has also added to the potential array of risks. These effects, and the contingency nature of how they can influence pension plans, are covered in the next two sections.

\section{The Pensions Act}

Several provisions of the Act are designed to provide for what has been described as "best practice" in the operation of occupational pension plans (5). Some of these provisions do not apply to money purchase schemes but to those schemes that are affected the deadline for compliance (or the beginning of a process leading to compliance) was April 1997. There are three areas of the Act that have the potential for influencing the way in which work place retirement plans are managed.

\section{Minimum Funding Requirement (MFR)}

This represents a legally-defined main stay for the pensions promise. Be defining the minimum basis upon which a scheme can operate, so as to safeguard the promise, the Act side-steps the controversy surrounding the ownership of scheme assets. Th Act neither refers to deferred pay, nor to company ownership and control. This omission probably reflects a wish by legislators not to disturb the delicate balance of interests represented by pension schemes. A neutral stance on this issue tacitly acknowledges the mutually-beneficial effects, without having to specify how different levels of employer and employee contributions might interact in terms of overall scheme influence. Such a proposition is supported by the fact that pensions remain under trust law, rather than being rest in terms of, say, contract law.

Under section 57 of the Act, the value of final salary scheme assets must be at least 90 per cent of the amount of the scheme liabilities. The liabilities refer both to the current pensions 
in payment and "deferred pensions" (pension benefits "owed" to scheme leavers), and to future payments to be made according existing terms and conditions.

Originally, this ratio was set at one, but was reduced to 0.9 in recognition of the type of assets that have traditionally been held by UK pension funds. On average, over 60 percent of such assets are held in the form of company ordinary shares (or equities), the majority of which are UK-listed, with rest being held in combinations of: fixed interest securities (usually referred to as bonds); "real" assets, such as property; and cash. One of the main problems facing actuaries in putting this standard in to practice is that the value of the equities is very time-sensitive. It is argued that using "point" or averaged value is inappropriate when what is required is some measure of the ability of a scheme to meet its obligations over the expected life of a scheme. Allowing the ratio of assets to liabilities to be less than one recognises both the inevitable short-term fluctuations in the market value of assets held be pension schemes, and the unlikely situation arising where all pension liabilties crystallise simultaneously.

Nonetheless, the MFR does act as an absolute yardstick against which scheme advisers must measure the condition of scheme assets. Such that, should there be a shortfall, a change in contributions, or in benefits, or both, is likely to result.

\section{Statement of Investment Principles (SIP)}

According to section 55 of the Act, an SIP must be issued annually by the trustees. This document must indicate trustees' policy regarding the following: the balance between different kinds of investment (usually referred to as "asset allocation"); the expected return on the investments; and risk (although the Act provides no guidance regarding how risk is to be measured). Nor does the Act provide a pro-forma version of the SIP. As a consequence, different versions are likely to appear, ranging from the short and the simple one-pager, to longer and more complicated multi-page statements, reflecting alternative interpretations as to what is practicable.

Irrespective of the level of detail issued and the extent to which sophisticated analysis and commentary is included in these annual statements, trustees will feel obliged to take greater interest than before in investment-related matters. Moreover, when combined with the MFR, 
the SIP renders more transparent to members the connection between the pensions promise and the means by which it is intended to be fulfilled.

\section{Member Nominated Trustees (MNTs)}

Section 16 of the Act requires at least two (or one if the scheme has less than 100 members), and at least one-third of the total be member-nominated. Pension scheme trustees are required to ask members to approve the existing appointment of trustees system (which may not be consistent with the Act), or introduce a new structure. The former procedure is known as an "opt-out", and involves the organisating scheme company in holding a ballot both of active and pensioner members. If 10 per cent (or 10,000, if scheme members exceed 100,000) object, trustees can seek permission of members to introduce tailor-made MNTs rules (which, again, may vary from the requirements of the Act). If these proposals are also rejected, "prescribed rules", which include the requirement to have one-third MNTs, are put in place.

Collectively, the MFR, SIP, and MNTs provisions, are likely both to heighten the awareness of scheme members, and make more onerous the monitoring role of trustees. The former may cause difficulties for the HR notion of the pensions promise, and the latter may lead to difficulties in recruiting scheme trustees, at least in the absence of some sort of trustees' insurance or indemnity. Moreover, as most schemes have senior executives as employernominated trustees, the potential conflicts between costs and benefits may become increasingly sharply drawn. The effects of this will be felt not only as the same set of executives move from pensions to planning meetings, but also when organisations seek to change the nature and operation of occupational pension plans; especially, if suggested alternations affect benefits or contribution levels, or both. This creates an incentive for organisations to seek ways of mitigating any adverse movements in the assets and liability characteristics of operating such schemes. This is another way of saying that the intertemporal effects of pensions need to be effectively managed which is tantamount to recognising the strategic implications of such arrangements. 


\section{Identifying the Risks}

What follows is intended to be check-list for managers concerned with capturing the more significant factors likely to influence both the sustainability of existing schemes, and the strategic challenges that the continued commitment, even when revised to cap the cost, of organisation-based pension plans.

\section{Regulatory Risk}

Complying with the requirements of the 1995 Act will raise the costs of operating occupational schemes (e.g. higher fees for advisers given the job of monitoring MFR and offering guidance on the contents of the SIP). This cost pressure alone could be sufficient to induce an employer to review the pension commitment.

In addition to the contingency allowance required to compensate for any shortfalls in the MFR, the Act provides power to the Occupational Pension Regulatory Authority (OPRA) to impose ad hoc "special" levies. These would be used by the Regulator to compensate scheme members for fraud, maladministration and incompetence. The level of provisioning for such an event would be for the trustees but it would be imprudent to assume the impossibility of another Maxwell scandal. If the reserved proved to be inadequate when called upon, then the solvency standard could be at risk of being breached.

There also exists the expectation of future pensions legislation, not only in terms of the proposed super-SIB, but Government plans for the so-called "stakeholders' pension" (6).

\section{Maturity risk}

Most UK pension schemes can be regarded as mature given that over 50 per cent of liabilities relate to pensions in payment and deferred pensions. Asset allocation, on the other hand, usually reflects the median peer-group strategy of fund managers (so-called "bench marking"), rather than the specific liability structure of individual schemes. Trustees charged now with making explicit how they intend to match asset allocations with scheme liabilities, as measured by the MFR, will have to be more precise than hitherto regarding investment policy.

The impact both of MFR and SIP on the maturity question becomes clear when the risks and returns available in the capital market are considered. In order to more easily satisfy the 
MFR, pension fund managers may be tempted to switch into bonds which provide a more stable basis for the valuation of the worth of scheme assets. Such switches are not costless because lowering of price volatility brings with it, on average and over the longer-term, lower rates of return. Lower returns translate into less investment income with which to meet pensions in payment. Over time, pension fund payments and receipts would have to be reconciled by increasing funding rates on employers, or employees, or both. Alternatively, pension payments could be reduced but this would be seen as a violation of the pensions promise.

\section{Market rise and Investment policy}

The SIP will also have an effect on asset allocation decisions, although this will vary across different schemes. Some may possess the necessary financial "slack" to withstand switches to assets with historically lower yields. Eventually some effect may be felt (such as, less generous attitude over discretionary matters, including early retirals) as trustees become concerned over the need to preserve the "main" commitment. For schemes where existing benefits are more sensitive to returns, pension managers have a limited set of options to offer trustees.

They could search for a class of assets capable of achieving aggressive returns but with hedging devices attached such that the asset valuation procedure is not compromised. However, the imagination of capital markets should never be underestimated, if such assets existed they would by now have been discovered, or invented. Alternatively, trustees could present questions directly to scheme members regarding the various investment strategies available, and indicating the associated outcomes in relation to pension benefits. Providing trustees felt that members' understanding was sufficient to enable them to adequately assess the various possibilities, then the interaction between trustees and members would become much more frequent and involved (and expensive to operate) than in the past. Improving communications may well be seen as a desirable position, and one indirectly hoped for by the Pensions Act, but presents as a possibility the creation of a sub-division of schemes. In that, members would be distinguished according to whether they wished to be risk-preferred, risk-neutral, or risk-averse. 


\section{Fiscal risk}

Saving for old age is not the only item on the politicians' agenda for promoting individual welfare provision. Tax-based incentives for individuals to buy insurance policies that cover several outcomes, including future health care costs, are likely to become more significant in the future. Consequently, a re-distribution of tax breaks across savings-related contracts can be expected, and such changes have the potential for affecting pensions plans at least as much as the Pensions Act.

For instance, the abolition of tax credits on dividends, announced in the July 1997 budget, effectively cuts the value of a pension fund's income from UK equities by 20 per cent. As a result, long-term investment returns achieved by pension schemes are likely to fall by 0.5 to 0.75 per cent, increasing the long-term cost of pension provision. The rise on costs could be more than 25 per cent of current costs for many final salary schemes (7).

\section{Strategic Response: Recasting the Pension Promise}

Given that many schemes are mature and compliance costs are on the increase, a legitimate question for senior management and trustees is whether a case exists for winding-up an existing scheme, and designing a replacement better aligned to

employment trends, and the regulatory and general business environments. Such options represent the strategic responses to the strategic challenges outlined in the previous section.

In particular, employers could move to money purchase schemes which are not covered by the MFR, thereby removing part of the contingent liability. Applying a funding standard to money purchase would be meaningless because the pension paid is a function of the investment performance of the fund; whereas, with a final salary scheme it is the assets that provide the basis for supporting the promise.

However, trustees in both types of schemes are required to issue a SIP which means having to reconcile competing forces. Employer-appointed trustees would be focused on present and future costs, and MNTs would be expected to be mainly interested in safeguarding pensions expectations. 
Such concerns partly explain the emergence of so-called "hybrid" schemes which comprise elements both of defined benefit and defined contribution. Under such schemes, the pensions promise relates the benefits paid to the performance of the fund but provides for a minimum pension, related to final salary, should the investment performance be deemed to be inadequate at the time an individual retires. The introduction of "menu-based" renumeration packages can also be seen to be part of the same trend. Menus allow individuals to select, amongst other things, the characteristics of the pensions promise (e.g. level of employer contributions), rather than relying upon trustees to conclude (well-meaning but inappropriate) compromises on behalf of employees.

Employers are attracted both to hybrids and the individualisation of pension arrangements (albeit under an employer umbrella) because they have the effect of containing the contingent liability nature of the pension commitment.

\section{Conclusions}

It is well understood that the rationale for providing work-based pension plans is a combination of factors associated with management beliefs. These beliefs are centred on the non-mutually exclusive desires both to be competitive in the skills market, and to be seen as having concern for employees' well-being. Measuring the effectiveness of pension plans has been, for the most part, the preserve of external advisers and asset managers. The main concern (and legal duty) of these groups is to maintain the ability of the scheme to meet its obligations.

Recent legislative change, and an expectation of more to come, has brought into sharp relief the need to balance the asset and the liability characteristics of such schemes, not least because of the more visible role now played by boards of trustees (both towards employers and employees) in the management of the pension promise which inevitably requires the risks to be carefully assessed.

Moreover, employers need to adequately assess the likely outturns of investment behaviour, tax, incidence, compliance costs, and managing employees' expectations because unexpected adverse movements in any of these has the potential for requiring transfers from employers' resources to the pension fund. Such financial "hits" have the potential both for weakening 
(further) the sustainability of the existing plan, and for frustrating well-argued (and often commercially imperative) development and change plans. 


\section{References}

(1) CBI/William Mercer Ltd (1994), A View from the Top: Senior Executives' Attitudes to Pension Provision, CBI/William Mercer, London

(2) Terry, N.G. and White, P.J. (1997), "The role of pension schemes in recruitment and motivation: some survey evidence", Employee Relations, Vol 19, no 2, 160-75

(3) Nobles, R. (1992), Controlling Occupational Pension Schemes, Institute of Employment Rights, London

(4) Terry, N.G. and White, P.J. (1995), "Occupational Pension Schemes: The Trade Union Dimension”, Industrial Relations Journal, Vol 26, no 4, 319-29

(5) Goode Committee (1993), Pension Law Reform, Cm 2342 - II

(6) Field, F. (1996), How to pay for the future, building a stateholders' welfare, Institute of Community Studies, London

(7) Financial Times (21 July 1997), reporting on the results of a survey by accountants Arthur Anderson 